\title{
GOBIERNO ABIERTO EN UNA PERSPECTIVA MULTINIVEL: REFLEXIONES ENTRE LA RAZÓN TEÓRICA Y LA INNOVACIÓN PRÁCTICA
}

\author{
Rafael Valenzuela Mendoza \\ El Colegio de Sonora, México \\ rafael.valenzuela1@gmail.com
}

\begin{abstract}
RESUMEN
Los países latinoamericanos que integran la Alianza para el Gobierno Abierto (OGP por sus siglas en inglés), han diseñado e implementado diversos mecanismos en la ruta hacia gobiernos abiertos. El análisis desarrollado en el presente artículo, sugiere la importancia de un abordaje multinivel en la operacionalización de gobierno abierto, donde lo multinivel dibuja el enorme reto de vincular acciones de gobierno y acciones de organizaciones de la sociedad civil, en una agenda común, que OGP denomina Plan de Acción. Las corrientes teóricas que abordan gobierno abierto, distinguen dos visiones, la tecnológica y la política, con la mira puesta en otorgar un sentido más colaborativo a la acción pública. Ambas, se articulan para otorgar sentido y dirección a la innovación práctica, específicamente en tres niveles de análisis: institucional (macro), organizacional (meso) y política pública (micro).
\end{abstract}

Palabras clave: Gobierno abierto, Transparencia, Participación, Colaboración, México. 


\title{
OPEN GOVERNMENT FROM A MULTILEVEL PERSPECTIVE: \\ REFLECTIONS BETWEEN THEORETICAL REASON AND PRACTICAL INNOVATION
}

\begin{abstract}
The Latin American countries which have joined the Open Government Partnership (OGP), have designed and implemented various mechanisms on the path towards open government. The analysis conducted in this paper suggests the importance of a multilevel approach to the operationalization of the open government, where the multilevel outlines the enormous challenge of linking government actions with those of civil society organizations in a common agenda which the OGP calls Action Plan. The theoretical approaches that address open government distinguish two visions, technology and politics, with focus on providing a more collaborative direction to public action. Both intertwine to give meaning and direction to practical innovation, specifically in three levels of analysis: institutional (macro), organizational (meso) and public policy (micro).
\end{abstract}

Keywords: Open Government, Transparency, Participation, Collaboration, Mexico. 


\section{INTRODUCCIÓN}

El objetivo del presente artículo es identificar los principales retos que enfrentan los países miembros del Open Government Partnership (OGP), al operacionalizar gobierno abierto. La importancia de concebirlo en una perspectiva multinivel adquiere singular relevancia, cuando se observa que cada país en América Latina adopta una definición de gobierno abierto con matices diferenciados, que conduce a identificar dos visiones, cada una define atributos particulares de orden tecnológico y político.

Tres niveles integran el marco analítico. En el nivel macro o institucional, se asocia al conjunto de reglas que habrán establecer el marco de la transparencia y participación ciudadana, componentes esenciales de un gobierno abierto. A nivel meso, se distinguen la visión tecnológica y política. La primera, asociada al uso intensivo de las Tecnologías de la Información y la Comunicación (TICs), liberación de datos útiles en formato reutilizable, plataformas interoperables y otros conceptos que devienen de un gobierno electrónico, éste último como antecedente directo de un gobierno abierto.

La segunda visión se identifica con la política pública de transparencia como condición para una participación ciudadana de efectos colaborativos, visión asociada a principios axiológicos de una forma particular de gobernanza y buen gobierno. Ambas son visiones yuxtapuestas, no necesariamente contrapuestas, que aportan insumos al razonamiento teórico en busca de correspondencia con una innovación práctica, que se enmarca en una concepción multinivel de gobierno abierto.

La construcción de ambas visiones, implica asumir el supuesto de una realidad mucho más compleja, y por lo tanto, la relevancia de adoptar dos casos que aporten evidencia que los atributos de cada visión no se presentan en forma pura en la realidad. La propuesta multinivel tiene la virtud de facilitar el diagnóstico, en ciertos contextos, para transitar hacia un gobierno abierto.

A nivel micro se ubica la política pública de gobierno abierto, donde la transparencia y la participación, son los medios para formar una estructura de incentivos en la definición de acuerdos, para el diseño e implementación de acciones concretas.

El artículo explora los casos de Chile y México, con el interés de conocer acciones asociadas a los tres niveles de análisis, en la implementación de la iniciativa de gobierno abierto, entre 2011 y 2013. Los criterios para seleccionar los casos son: 1) que uno tenga la calidad de fundador del OGP y el otro sea miembro activo; 2) que se trate de países con más desarrollo en 
gobierno electrónico de acuerdo a la Comisión Económica para América Latina y El Caribe (CEPAL); y 3) que sean referencia en su política pública de transparencia. Estos criterios, conducen a seleccionar a los únicos dos países latinoamericanos que han sido sede de los únicos dos encuentros regionales del OGP.

Al final se aporta una reflexión que describe algunos aprendizajes y define los retos más relevantes en términos de futuras líneas de investigación.

\section{¿QUÉ ES EL GOBIERNO ABIERTO?}

El Gobierno abierto se reconoce como un concepto en construcción, aunque existe amplio consenso en torno de sus componentes principales: transparencia, participación, colaboración y rendición de cuentas (Valenzuela 2012, Mariñez y Valenzuela 2013). En 1957, se utiliza por vez primera el concepto open government (gobierno abierto), en el artículo "The Open Government Principle: Applying the Right to Know Under the Constitution", publicado en George Washington Law Review, de Wallace Parks, una década previa a la promulgación de la Ley Federal de Libre Acceso a la Información Pública (FOIA por su sigla en inglés) de los Estados Unidos de Norteamérica (Jiménez 2013).

Entre las definiciones más citadas de gobierno abierto, se encuentra una que establece que se trata de un gobierno que entabla "una constante conversación con los ciudadanos, con el fin de oír lo que ellos dicen y solicitan, que toma decisiones basadas en sus necesidades y preferencias, que facilita la colaboración de los ciudadanos y funcionarios" (Calderón y Lorenzo 2010: 11). Otros expertos argumentan que se trata de una "doctrina política que se opone a la razón de Estado" (Guardián 2010: 76).

No debe soslayarse que un gobierno es la expresión institucional de la autoridad del Estado, cuya función básica consiste en la conducción política, y desarrollar las atribuciones encomendadas en el ordenamiento constitucional, a través de órganos legítimos y democráticos. Todo gobierno conserva una estructura de poder político que limita su ejercicio, en virtud del principio de legalidad, las garantías individuales y los derechos humanos.

Para que transitar hacia un gobierno abierto, resulta clave modificar estructuras de poder tradicionales, para abrir canales relacionales con la ciudadanía, modificar su forma de organización para proveer información pública y crear incentivos para el acceso del ciudadano a la arena decisional, esto es, hacer más pública la hechura de la decisión de política y lograr mayor incidencia ciudadana en los asuntos públicos. 
Ello tiene implicancias en las empresas, organizaciones de la sociedad civil y ciudadanos, donde el gobierno añade más transparencia, para "dar a conocer cosas -obtener información relevante y comprensible-; hacer cosas -obtener servicios y realizar transacciones desde y con el Gobierno-, y crear cosas -participar en el proceso de toma de decisiones-" (Ramírez 2011: 107).

Meijer et al. (2012: 13) define el gobierno abierto como el "grado en que los ciudadanos pueden monitorear e influir en los procesos gubernamentales a través del acceso a la información pública y el acceso a la arena donde se toma la decisión”. Otras referencias más cercanas definen el gobierno abierto desde la práctica, como Naser y Concha (2012), que lo ubican como la siguiente generación de gobierno electrónico, o como sugiere Gascó (2013: 1), es "la evolución de la incorporación de las tecnologías de la información y las comunicaciones (en adelante, TIC) al ámbito público $[\ldots] "$.

Al poner en un mapa las definiciones comúnmente aceptadas, podemos visualizar que gobierno abierto es un concepto multinivel, que se reproduce transversalmente, atendiendo el contexto particular de cada gobierno y sociedad. Tres niveles se concatenan con dos visiones, que se describen enseguida.

\section{Gráfico 1: Modelo de análisis multinivel de gobierno abierto}

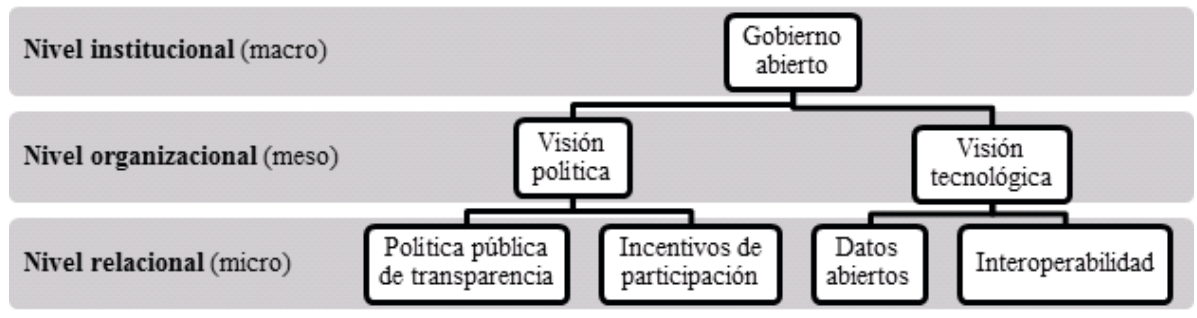

Fuente: Elaboración propia.

\section{HACIA UNA CONCEPCIÓN MULTINIVEL DEL GOBIERNO ABIERTO}

La propuesta teórica-metodológica para el análisis de un gobierno abierto comprende tres niveles. El primero refiere un nivel macro, que atiende las instituciones y el conjunto de valores que representa gobierno abierto. En el segundo nivel de análisis (meso), refiere a la forma de organizar el gobierno, con la mirada puesta en abrir gobiernos desde dentro, pero 
también formas de organizar la sociedad, para abrir el gobierno desde entorno, por medio de organizaciones de la sociedad civil, siguiendo la idea de Popper (2006), de una sociedad más abierta al razonamiento deliberativo y al conocimiento crítico. Internet, y en general las TICs, han sido un detonante para ello.

En un tercer nivel que se denomina micro, es donde la política pública y los actores se hacen presentes en el diálogo, consenso y se comunican para compartir problemas y soluciones. En este último nivel, el OGP ha jugado un papel central para mejorar las condiciones y afinar instrumentos de cambio, en torno a la relación tradicional de los gobiernos con la sociedad civil, y como ésta se vincula con aquellos.

\section{INSTITUCIÓN POLIÁRQUICA: NIVEL MACRO}

El primer nivel agrupa el conjunto de instituciones y principios constitucionales, que definen un marco propicio para sentar las bases de un gobierno abierto. A este nivel se atisba el primer componente del gobierno abierto: la transparencia. Por décadas, concepto y componente se asimilaron sinónimos. Un gobierno abierto como institución, sugiere un marco poliárquico, donde la variedad de fuentes de información, la libertad de asociación y el derecho de petición, adquieren vigencia y se positivizan para fortalecer la democracia (Dahl 1992).

A partir de la incorporación de tales instituciones como principio constitucional y axiológico, el gobierno abierto es una institución que define el marco de acceso a la información pública (Uvalle 2013). Justamente, Parks (1957) refiere el término open government como principio constitucional. La vinculación a las instituciones de la poliarquía sugiere que el gobierno abierto está en el marco de las democracias, no como regla de acceso al poder, sino como ejercicio de éste en pleno respeto, se reitera, de la variedad de fuentes de información, la garantía de libertad de asociación y el derecho de petición.

El antecedente histórico concibe el gobierno abierto como condición necesaria de una mayor transparencia y acceso a la información pública. Se infiere, por lo tanto, que el concepto se asoció a un tipo de transparencia legal y organizativa, que hoy en día pudiera parecer lejano, si se contrasta con la transparencia basada en datos abiertos. Sin embargo, las deficiencias persisten en los tres tipos de transparencia. A este nivel de análisis, existen rasgos característicos que promueven y alientan mecanismos de publicidad de las decisiones del Estado, guiados por un marco normativo de derecho, para definir los términos de apertura y publicitación, valores políticos inherentes de una sociedad abierta (Fung y Weill 2010). 
El carácter deliberativo, colaborativo y plural, son los elementos que otorgan viabilidad a una política democrática de gobierno abierto. Bajo una competencia plural basada en la razón pública, expuesta por grupos de la sociedad civil, los actores con voz impulsan temas, problemas y soluciones en un proceso dialógico con el gobierno. Así, es preciso destacar que el gobierno abierto denota el valor de lo justo, expresado en la escucha de una multiplicidad de actores con voz.

El atributo de la deliberación en el gobierno abierto sugiere la existencia de una conversación de individuos, que hablan y escuchan consistentemente, antes de tomar una decisión colectiva (Habermas 2005, Elster 2001, Cohen 2001). Estas conversaciones se ubican en un continuum de dos extremos: Por un lado aparece la negociación, que implica intercambiar promesas, amenazas o bienes y, por otro lado, está el razonamiento que se ubica en la cartografía de los hechos y las causas (Gambetta 2001).

En consecuencia, la deliberación alude a un proceso previo de la decisión, de efecto positivo o negativo bajo determinadas condiciones específicas. Las consecuencias positivas guardan relación con la mejor distribución de la información, puesto que la habilidad de informar y razonar tiene que equilibrarse en la deliberación. En el marco del proceso de distribución y acceso a la ciudadanía de datos, información y conocimiento, resulta una trilogía o bien altamente preciado y valorado. Por lo tanto, la deliberación es un intercambio, dialógico y de negociación que puede convertirse en un mercado de regateo, dada la naturaleza del intercambio.

Bajo ciertas condiciones, está latente el riesgo de una deliberación sin colaboración, lo que vuelve porosa la base de confianza que emerge entre gobierno y ciudadanos, cuando se trata de tomar una decisión colectiva. El gobierno abierto aspira transitar del ideal deliberativo, hacia la práctica colaborativa. Por años la deliberación ha sido cuestionada como ideal democrático, por traducirse sólo en consultas ciudadanas que no se reflejan en decisiones públicas. La práctica del ideal colaborativo se presenta como método particular para el diseño e implementación de soluciones a los problemas públicos.

Beth Noveck (2010) ilustra algunas de las diferencias entre la democracia deliberativa y democracia colaborativa. Ambas tienen en común la importancia de la ciudadanía, y suponen la existencia de grupos organizados de la sociedad civil. 


\section{Tabla 1: Diferencia entre democracia deliberativa y democracia cola- borativa}

Deliberación (Habermas)

Requiere de un agenda para su discusión

Se basa en la conversación y capacidad de argumentar los asuntos para decidir

Sustenta su razón en la calidad de procedimiento democrático

El consenso es deseable como un fin en sí mismo

Se basa en la propia expresión de ideas

La deliberación ocurre antes de implementar una decisión o política
Colaboración (Noveck)

Requiere descomponer un problema para su solución

Se basa en habilidades para hacer y la capacidad para conectarlas a la acción pública

Sustenta su razón en la efectividad de la decisión y sus resultados

La colaboración es un medio para lograr diversos fines

Se basa en la participación

La colaboración ocurre durante el proceso decisorio en el diseño e implementación

\section{Fuente: Elaboración propia con información de Noveck (2010).}

La deliberación establece mecanismos para procesar el conflicto, la negociación y el consenso, mientras que la colaboración se constituye como medio para lograr múltiples oportunidades para mejorar la calidad de la decisión, implementar más eficazmente el proceso decisorio y evaluar, en su oportunidad, la política pública de gobierno abierto. De ahí la relevancia de comprender los términos de la colaboración, como práctica inclusiva de apertura gubernamental.

Abrir los espacios de colaboración en la gestión de lo público gradualmente materializa una sociedad más abierta que tiende a resolver sus problemas junto al gobierno, dentro del proceso de la política, y no al margen. La deliberación tiende a ocurrir en cualquier organización política, y se constituye como eje central de una política democrática (Deutsch 1998: 197).

Un gobierno abierto promueve la deliberación basada en el intercambio libre de información, donde se manifiestan posturas y se demanda conocimiento acerca del hecho o problema público, La deliberación sustentada en el método de la colaboración, prevalece un pluralismo razonable, como el que alude Rawls (2005), sustentado en ideas, propuestas y soluciones, expuestas en condiciones de cierta igualdad y racionalidad. 


\section{LA VISIÓN PARA ORGANIZAR EL GOBIERNO Y LOS ACTORES SOCIETALES: NIVEL MESO}

Por organización, entenderemos un conjunto de mecanismos de coordinación para el trabajo (Vergara 2010: 17). El éxito de las organizaciones depende, además, de varios factores adicionales a la coordinación y control eficientes de las actividades que realiza en ambientes complejos organizativos. En la década de los setenta, EL gobierno abierto se presenta como la apertura de ventanas del gobierno (Ramírez 2011), lo que perfila cierta forma de organizar el gobierno. Aun cuando se acepta que las organizaciones son sistemas flojamente acoplados, donde la misión, visión, procesos, procedimientos y rutinas, pudieran estar débilmente alineados, en un ambiente de problemas e incertidumbre; la globalización y el cambio tecnológico resultan factores que incentivan un contexto, donde la organización moderna dejó de ser un sistema cerrado, simple y de certidumbre total en sus procesos y resultados.

Repensar el papel de la burocracia en un sentido moderno avizora un horizonte de racionalidad limitada, que podría resultar menos limitada, de aplicar fórmulas colaborativas entre gobierno y sociedad, y que reduzcan asimetrías en la información. Lo anterior conlleva despojarse de supuestos esquemas que asignan a la sociedad una pureza total y al gobierno una impureza fuera de duda. Conceptualizar la organización burocrática del Estado al margen de dogmas, es fundamental, y en esa medida "[...] dejar de difamar al servicio público. Cualquiera que sea la retórica sobre la 'burocracia', las organizaciones no son el enemigo. Son las herramientas más efectivas que los seres humanos hemos desarrollado para satisfacer las necesidades humanas" (Simon 2001: 121).

La revolución digital ha favorecido un nivel de modernización nunca antes visto, no sólo en la organización gubernamental, sino en la organización privada y social, lo que atinadamente refiere Arellano (2010: 89), como "un constante proceso de organizando". Cuando se trata de organizaciones basadas en rutinas y tecnologías de producción, el éxito dependerá de la eficiencia (Meyer y Rowman 2001: 94). En la actualidad, las organizaciones enfrentan un gran número de contingencias que les exige controlar, en lo posible, la incertidumbre que se produce en los intercambios y rutinas. La capacidad de adaptación a los cambios en la sociedad, es clave para entender las organizaciones que sobreviven a irrupciones no previstas, por ejemplo, ambientes financieros, económico, social, productivo y político, entre otros.

La adaptación conlleva un proceso de cierto grado de homogenización, es decir, amoldarse o parecerse a los cambios instrumentados en otras 
organizaciones similares. Este fenómeno se identifica como isomorfismo, definido como un "proceso imitador que obliga a una unidad, en una población, a parecerse a otras unidades que enfrentan las mismas condiciones ambientales" (Powell y DiMaggio 2001: 108). El isomorfismo es un concepto útil para entender la política organizacional y que auxilia en la explicación del cambio institucional. DiMaggio y Powell (2001) identifican tres mecanismos por los cuales ocurre el cambio:

1) el isomorfismo coercitivo, que se debe a influencia políticas y al problema de la legitimidad; 2) el isomorfismo mimético, que resulta de respuestas estándares a la incertidumbre, y 3) el isomorfismo normativo, asociado con la profesionalización (Powell y DiMaggio 2001: 108).

El gobierno abierto no se explica al margen de la teoría organizacional. El proceso de cambio en las organizaciones públicas que sucede al implementar un gobierno abierto puede tener éxito si la organización dispone de resiliencia. Ésta se define como la habilidad de ciertas organizaciones para resistir fuertes momentos de crisis, debido al desarrollo de nuevas capacidades o un choque en particular que sacude a la organización. Tal habilidad tiene el atributo de recuperar una nueva situación de estabilidad y equilibrio, "actuando como un sistema adaptativo, que enriquece su complejidad interna para hacer frente a la creciente complejidad del entorno" (Rochet et al. 2008: 66).

La homogenización, el isomorfismo y la resiliencia, invitan a reflexionar la organización en forma de rutinas, procesos, reglas y actores que articulan la visión política y la visión tecnológica del gobierno abierto. El Estado moderno es la organización pública mediante la cual la sociedad asigna valores a lo público y distribuye el poder político, pero ya no en forma de sistema cerrado, sino que utiliza la retroalimentación en forma de un sistema abierto y permeable al avance tecnológico y formas políticas de gobernanza abierta y colaborativa.

Cuando el pluralismo asociado al gobierno abierto se activa, la multiplicidad de actores sociales y actores políticos dan forma a múltiples polos de influencia en la acción pública. La organización gubernamental requerirá ir descubriendo nuevas formas para determinar políticas, facilitar la coordinación y mejorar la eficiencia. Cada uno es un reto central para la burocracia en un gobierno abierto. Weber (2005) define la burocracia como una forma de organización en la que descansa el Estado, para ejercer su función administrativa, caracterizada por establecer jerarquías y sectores organizados por competencias. Su concepción pública, legal y racional, tiene dosis de una instrumentalidad administrativa que define 
una organización moderna del servicio civil.

A partir de la adopción de la Nueva Gestión Pública, el Estado también descansa en las organizaciones privadas para proveer servicios públicos. No obstante, la administración pública legal y racional estilo Weber, define la división de funciones basadas en la competencia, lo que refleja cierto nivel de fragmentación administrativa. Quienes abordan la fragmentación como problema, corren el riesgo de evitar analizarlo en términos de efecto y causa de fenómenos sociales y políticos, que se suponen deseables en una democracia, considerando que la fragmentación está asociada a un pluralismo político y social que antańo era inoperante.

El terreno empírico da muestra de una fragmentación con un pluralismo no comunicado o coordinado, lo que deviene en limitaciones operativas en la organización pública. Scott y Meyer (2001), reiteran lo anterior al afirmar que "[...] la fragmentación está indicada ya sea por una gran cantidad de lugares no coordinados de toma de decisiones en un nivel determinado o por una gran y variada cantidad de vías o canales que se usan para transmitir decisiones" (Scott y Meyer 2001: 181).

En países donde predomina la sociedad abierta a la participación de los asuntos públicos, los gobiernos se obligan a instrumentar medidas que, necesariamente, significa coordinarse entre los distintos órdenes de gobierno. La importancia de la integración back offce (Jiménez y Gascó 2012), toma significativa relevancia para lograr la interoperabilidad organizativa, mediante marcos de interoperación que intentan crear, mejorar y producir efectos de mayor nivel de comunicación y colaboración en la gestión gubernamental. Esta transformación está en la línea de la modernización de la Administración Pública.

La plataforma del gobierno abierto es tecnológica, por cuanto atiende al back office, pero también es política cuando se alude la relación front office de un gobierno abierto a la ciudadanía, y una ciudadanía abierta a tomar partida en los asuntos públicos.

El eje de colaboración en el gobierno abierto se sustenta en las estrategias de intercambio de información y comunicación, así como el desarrollo de aplicaciones tecnológicas, pero sin marginar la importancia de las condiciones políticas que favorecen su instrumentación. Para Vercelli (2010: 262), "las tecnologías no son neutras", tienen una historia que define el rumbo de la codificación y solidificación de las relaciones. Las tecnologías con las que se vayan a construir un gobierno abierto serán resultado de luchas e intereses de los diferentes grupos sociales por el uso y el manejo de la información. 
El debate actual muestra que las aplicaciones de gobierno electrónico son la cara visible y más socializada del gobierno abierto. La visión tecnológica de gobierno abierto promueve la creación y el uso de aplicaciones digitales a partir de la información pública, en forma de datos abiertos, en la búsqueda de una relación interactiva entre ciudadanos, y también entre órdenes de gobierno.

\section{Política y tecnología para organizar lo abierto del gobierno}

La visión política del gobierno abierto reconoce en su esencia un carácter político y democrático, además de cumplir una función reguladora en el sistema político. El rápido desarrollo tecnológico en la era del conocimiento, y la aparición de fenómenos como la globalización y mercados débilmente regulados, son factores que definen múltiples centros de poder, donde los gobiernos dejaron de ser actores únicos. Es el despertar de una sociedad cada vez más activa que demanda la aplicación de sus soluciones a demandas sociales.

La transparencia, la participación ciudadana y la colaboración, en tanto componentes de un gobierno abierto, se definen en términos de una visión política institucional y plataforma democrática, mientras que la visión tecnológica define esos mismos componentes en términos de una plataforma digital y co-creación de valor público.

La visión tecnológica indica que la irrupción de Internet, con cada vez más amplio acceso social, se fortalece en una tradición de gobierno electrónico, como estrategia central para reforzar la igualdad de la participación ciudadana. Ambas son condiciones mínimas para la viabilidad de un gobierno abierto. La apertura está determinada por una sociedad en red, como fenómeno que despierta amplias oportunidades de informarse, para influir en las decisiones de los gobernantes. Esta visión asume que el fenómeno de Internet viene a empoderar al ciudadano.

Las visiones política y tecnológica de un gobierno abierto están yuxtapuestas, pero son complementarias. Mientras que la política es comúnmente obstáculo para instrumentar LA tecnología en el gobierno, la tecnología viene potenciando cada vez la relación hacia fuera del gobierno con el sector social y privado. Aun siendo complementarias, existen algunos puntos donde cada visión pone énfasis particular.

En una visión política importa más la concepción del gobierno en el espacio de lo público, como institución que reconoce la interdependencia de sus componentes, mientras que a la visión tecnológica le interesa una concepción de lo abierto en forma de espacio virtual, que reconoce la 
interconexión de sus componentes en forma de nodos.

Respecto del primer componente de un gobierno abierto, la transparencia, la visión política crea marcos institucionales que protegen el derecho de acceso a la información pública en el marco de una gestión de la calidad de la información. Mientras, la visión tecnológica reconoce que los portales de Internet y los repositorios de datos abiertos fortalecen el acceso a la información.

Respecto al segundo componente del gobierno abierto, la participación, la visión política ubica la capacidad de inclusión del ciudadano en la gestión y la política pública, y el acceso a la arena decisional, como lo relevante. Mientras que la visión tecnológica ubica relevante los niveles de empoderamiento de la sociedad y da un mayor énfasis en fortalecer las redes sociales, mediante procesos basados en tecnología y una ética hacker. La visión tecnológica de la colaboración, pretende reducir la capacidad regulatoria del gobierno hacia la sociedad, en virtud de un empoderamiento social que deviene de la nueva realidad tecnológica, así como el creciente uso de Internet en los procesos políticos, sociales y económicos (Fuster y Subirats 2013). Esta visión, circunscribe la colaboración en términos tecnológicos, como la capacidad de intercambio de información. El reto planteado en esta visión es alcanzar la capacidad de procesamiento de altos volúmenes de datos por parte de la sociedad, mediante la transformación de datos públicos, puestos a disposición del público interesado en acceder a información pública (Oszlak 2012).

La visión tecnológica supone una ciudadanía activa e interesada en aportar soluciones a los problemas públicos, lo cual suena congruente con la anhelada demanda de participación ciudadana en los asuntos públicos. El canal para ello está en el uso de los recursos tecnológicos, que vienen a fortalecer la e-democracy o el e-government (Fuster y Subirats 2013, Subirats 2012), en lugar de cuestionar el cómo de aquello que se viene haciendo. Así, el recurso tecnológico aparece como medio para hacerlo de forma más eficiente.

En la visión política del gobierno abierto, éste se asume como causa de mejores condiciones de legitimidad democrática, pero es imprescindible potenciar las capacidades institucionales y organizativas, para responder a las demandas sociales, y ahí es donde las TICs son herramienta central para lograr ese efecto. La visión política asume que el gobierno abierto (nivel meso) es una organización productora de valor público, dentro de un entramado legal y constitucional que aspira a gobiernos más transparentes y participativos, cuyo efecto esperado es la eficacia de resultados en beneficio colectivo. Por ello, el principio de máxima publicidad en el ejercicio del 
poder político, mandato ineludible para proveer información pública, para posibilitar la producción de valor público.

Las vicisitudes y conflictos propios de los sistemas políticos, como la transición de administraciones públicas tradicionales hacia formas más abiertas de relacionarse gobierno y sociedad, invitan a cuestionar el modelo vigente de gestión pública, y escudriñar el modelo de gestión que un gobierno abierto supone trazar, en la ruta hacia un enfoque basado en un nuevo servicio público (Denhardt y Denhardt 2000, Mariñez 2013).

El valor de la colaboración se comprende con mayor exactitud al analizarlo como resultado de condiciones institucionales, organizativas, relacionales y tecnológicas, que permiten conjugar la transparencia y participación, con efectos que apuntan al fortalecimiento de una mayor colaboración entre gobierno y sociedad (Valenzuela 2013). El terreno empírico muestra que en América Latina, aún prevalecen administraciones que persiguen la legalidad como valor supremo, la rendición de cuentas de la burocracia hacia el político electo y reducidos espacios de intervención de la ciudadanía en lo público gubernamental, pero, sobre todo, prevalecen administraciones basadas en la desconfianza de la participación ciudadana. Como si la información pública estuviera en propiedad del servidor público, y no en una custodia responsable.

\section{LA POLÍTICA PÚBLICA DE GOBIERNO ABIERTO: NIVEL MICRO}

Los niveles macro y meso de una concepción multinivel de gobierno abierto, indican que las instituciones y las organizaciones, importan para lograr el efecto colaborativo entre gobierno y sociedad. No obstante, en el nivel micro la política pública permite traducir los problemas asociados al gobierno abierto en soluciones de política pública vinculados a sus componentes más habituales e identificables: la transparencia y participación. Aunque se trata de componentes transversales en una concepción multinivel de gobierno abierto, la relación que guarda entre ambos, no es estable o inmanente. Tampoco tiene efectos positivos perdurables, ya que, en ocasiones, tiene externalidades negativas. Meijer et al. (2012) establecen tres tipos de relación entre transparencia y participación.

La primera relación, de tipo ideal, predomina la sinergia entre los dos componentes. Bajo este supuesto, la transparencia garantiza el total acceso a la información pública y la participación está garantizada por el mismo gobierno, y así provee al gobierno de conocimiento ciudadano para la toma de decisiones. Esta relación tipo ideal, existen dos posturas en términos del diseño e implementación de la política pública. 
Una primera postura argumenta que el acceso a la información es una condición previa para lograr la participación ciudadana en la toma de decisiones, toda vez que el ciudadano tiene la obligación de saber, conocer y estar informado, y entonces decide participar en los asuntos públicos enlistados en la agenda gubernamental. Una segunda postura, sostiene que el acceso a los espacios de toma de decisión es la condición previa sine qua non para ejercer el acceso a la información, toda vez que ciertos documentos y otro tipo de información están generalmente reservados a políticos tomadores de decisión. Por lo tanto, se infiere que a nivel macro institucional, operan reglas que favorecen una visión basada en la publicidad, si referimos a la transparencia, mientras que a nivel meso organizacional, se precisa asegurar canales efectivos de acceso a la arena de la decisión en los asuntos públicos. La sinergia entre la transparencia y participación, refleja una correspondencia múltiple entre el nivel institucional y el nivel organizacional de un gobierno abierto.

Una segunda relación entre transparencia y participación, asume cierto grado de complementariedad. Mejier et al. (2012), postulan que, bajo ciertas circunstancias, la participación cívica se activa a través de mecanismos de transparencia, pero en otras la lógica es inversa, la transparencia es activada por la vía de la participación. Por ello Meijer et al. (2012), sugieren que en la política pública de gobierno abierto es esencial establecer en la etapa inicial del diseño de la política vías efectivas de participación ciudadana para formular el problema público y su solución, mientras que en la etapa de implementación de la política pública importa más la transparencia con la cual se instrumenta, puesto que el responsable principal de ello es el gobierno.

Una tercera relación, denominada de socavación, supone que la transparencia puede minar la participación y también viceversa. Esta relación describe efectos negativos. Resulta oportuno apuntar un estudio de Associated Press, citado por Gascó (2013), con el cual evalúan marcos legales de transparencia y acceso a la información pública en trece países de Latinoamérica. Destacan Chile, República Dominicana, Guatemala, México y Uruguay, cinco países que cumplieron en tiempo y forma legal, otorgando puntual respuesta a las peticiones de información pública, lo que representa el $38 \%$ de los países que cumplen con las reglas de transparencia ${ }^{1}$. Perú entregó información parcial (8\%), mientras que Colombia, Ecuador y Panamá (23\%) respondieron con alguna información que no resultó útil al ejercicio. Brasil, El Salvador, Honduras y Nicaragua (31\%), ignoraron dichas solicitudes por completo.

1 Las trece naciones son Brasil, Chile, Colombia, Ecuador, El Salvador, Guatemala, Honduras, México, Nicaragua, Panamá, Perú, República Dominicana y Uruguay (Gascó 2013). 
Lo anterior indica la existencia de marcos legales, institucionales y organizativos de transparencia, que pudieran socavar la transparencia misma. Y ello implica que no se producen efectos inmediatos en el otro componente, la participación. Ello implica una forma de socavación que Meijer et al. (2012) no identificaron. La idea de socavar, implica la obstrucción de un componente sobre otro. Sin embargo, la evidencia empírica parece aportar elementos de análisis en torno de un cuarto tipo de relación entre transparencia y participación, que complementa la reflexión de Meijer et al. (2012).

Se trata de una relación de efecto nulo entre ambos componentes, es decir, no existe afectación o beneficio de uno hacia otro componente. Se trata de un tipo de relación que se propone con base en evidencia que sugiere que los componentes de gobierno abierto, pueden correr en pistas separadas. El estudio de Welch (2012), basado en un análisis de regresión de múltiples variables de transparencia y participación a nivel de gobierno local, permite identificar hallazgos relevantes, en tanto indican que la participación ciudadana está "positivamente asociada con la transparencia, pero al revés no se sostiene el argumento; la transparencia no siempre conduce a mayor participación" (Welch 2012: 95).

Esta línea de reflexión apunta a proponer una cuarta de relación entre ambos componentes, donde la existencia de un componente no habilita la eficacia del otro, mucho menos crea sinergias, pero tampoco lo socava. Se trata de una relación de efecto nulo, donde la transparencia y la participación ciudadana, se manifiestan de forma separada e independiente, a la espera fluir conjuntamente ${ }^{2}$. Esta cuarta forma relacional entre transparencia y participación requiere identificar condiciones que promuevan la conjunción de ambas corrientes separadas e independientes. La idea de los componentes como flujos facilita una comprensión más sistémica del gobierno abierto.

\section{La brecha entre la teoría y práctica de un gobierno abierto}

El razonamiento teórico de un gobierno abierto pone de manifiesto la existencia de principios políticos liberales como la transparencia, y otros republicanos como la participación ciudadana, que se articulan en una propuesta de gobernanza muy particular, más abierta y colaborativa, cuyos fines permiten ser alcanzados mediante la innovación y el uso eficiente de las TICs.

2 Esta conclusión forma parte de un proyecto de investigación doctoral concluido en diciembre de 2013, en el que se analizan los casos de Chile y México, entre 2011 y 2013. 
La frontera trazada entre la visión instrumental de corte tecnológico y la visión valorativa de orden político adquiere nitidez a partir de los resultados obtenidos en la implementación de la directiva del presidente Obama (2009), que al paso del tiempo se fue decantando por una más visión pragmática e instrumental de gobierno abierto, basada en la innovación en el sector público. Beth Noveck, Jefa de la Oficina de Innovación de la Casa Blanca en la primera administración de Obama (2009-2012), al dejar su cargo destacó ciertas reservas respecto al uso otorgado a open government,

[...] en retrospectiva, (el término) gobierno abierto fue una mala elección (en la directiva de Obama). Se ha generado mucha confusión. Muchas personas, incluso en la Casa Blanca, todavía asumen que el gobierno abierto significa transparencia en el gobierno (Yu y Robinson 2012: 204).

La idea motivó a Noveck, primero como profesora universitaria y después como funcionaria del gobierno federal de Estados Unidos, a innovar en los procesos de gobierno para ofrecer eficiencia y eficacia en los servicios públicos, mejorar su desempeño mediante el uso y generación de mayor información pública, necesaria para desarrollar aplicaciones tecnológicas, que a su vez, favorecen la creación de valor público.

De esta forma, las acciones de la política de datos abiertos (open data policy) son insumo para el desarrollo de las tecnologías en la innovación del sector público y privado, como lo postula la autora de Wiki-government (Noveck 2009). La política pública de gobierno abierto (open government policy), tiene objetivos que definen un marco valorativo de la sociedad, en la búsqueda de gobiernos más transparentes y responsables. Aun cuando la práctica de gobierno abierto se asocia, con mayor énfasis, con la innovación tecnológica de procesos gubernamentales, la teoría basada en la razón del diálogo y la crítica colaborativa, precisa de ambas visiones como fuente complementaria en la definición de un gobierno abierto, y no visiones encontradas sin posibilidad de coexistir. Las relaciones modernas no se conciben sin el uso de la TICs, de igual forma que las tecnologías no están vacios de valores y principios de política pública.

\section{Los flujos de la transparencia, la participación y la colaboración}

Una transparencia sin vigilantes equivale a reglas sin eficacia, que conducen a más transparencia sin resultados e información sin valor público. Los países latinoamericanos en el OGP brindan una ventana de oportunidad para facilitar la convergencia de flujos de transparencia y participación. La apertura gubernamental del calibre que propone OGP, ha sido posible de impulsar mediante una sociedad civil organizada, pero también como 
resultado de la crisis de confianza en las instituciones públicas.

Otros factores asociados a la apertura del gobierno son la penetración de Internet en el espacio público y privado y el monitoreo de organismos internacionales para diseñar instrumentos internacionales de combate a la corrupción ${ }^{3}$. Lo anterior, viene a sentar bases mínimas, que se combinan para introducir nuevos conceptos articuladores de la relación gobierno, sociedad y mercado. De ahí que el gobierno abierto genere altas expectativas en torno del diseño y de implementación de políticas que intentan resolver nuevos y viejos problemas de la vida asociada.

\section{Figura 2: Los componentes de gobierno abierto en forma de flujos}

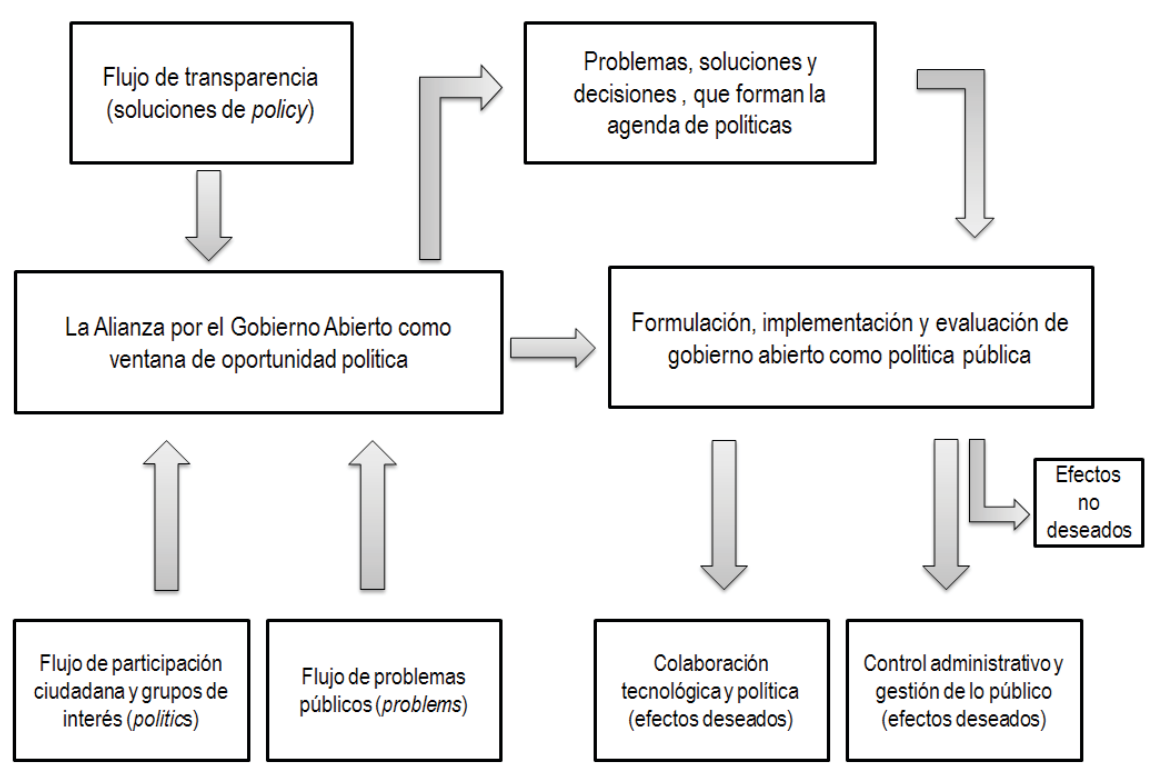

Fuente: Elaboración propia.

Villoria (2012) sostiene que el gobierno abierto es un subsistema de política pública, formado por actores y organizaciones involucradas en la solución de algún problema público. Del subsistema se infieren cuatro tipos de gobierno que busca un gobierno abierto. El primero refiere a un

3 Como el caso del Mecanismo de Seguimiento de la Convención Interamericana de Combate a la Corrupción (MESISIC) de la Organización de Estados Americanos (OEA), explican por qué en sus inicios se buscó transparentar la gestión de los gobiernos nacionales. 
[...] gobierno promotor de bienestar a través de la capacidad regulatoria. 2. Las del gobierno transparente que rinde cuentas. 3. Las del gobierno participativo y promotor de civismo. 4. Las del gobierno eficiente, colaborador y generador de conocimiento (Villoria 2012: 6).

La tipología de Villoria (2012), basada en la regulación, la participación, la transparencia y la colaboración, atisba corrientes de cierta independencia, que parecen corresponder a la idea de flujos múltiples.

\section{LA ALIANZA DE GOBIERNO ABIERTO: UNA VENTANA DE OPORTUNIDAD}

En septiembre de 2010, el presidente Obama lanzó el reto a los países del orbe para constituir una alianza global en la búsqueda de gobiernos que respondan de forma más eficaz a lo público. La Casa Blanca convocó a líderes de gobierno y ciudadanos a constituir el OGP y Brasil se propone como co-líder, y junto con Indonesia, México, Noruega, Filipinas, Sudáfrica y el Reino Unido, más nueve representantes de sociedad civil, Instituto Mexicano de la Competitividad, el African Centre for Open Governance de Kenya, el Instituto de Estudos Socioeconômicos (INESC) de Brasil, el International Budget Partnership, el MKSS de India, el National Security Archive de Estados Unidos, el Revenue Watch Institute, Transparency and Accountability Initiative, y Twaweza de Tanzania, formalizaron en septiembre de 2011 el OGP.

El OGP intenta promover los principios de transparencia, participación, rendición de cuentas e innovación tecnológica en cinco grandes ejes temáticos: 1) mejoramiento de servicios públicos; 2) aumentar la integridad pública; 3) mejorar la gestión eficaz de recursos públicos; 4) crear comunidades seguras; y 5) rendición de cuentas corporativas.

El marco institucional normativo que fundamenta el OGP son la Declaración Universal de los Derechos Humanos, la Convención de las Naciones Unidas contra la Corrupción y otros instrumentos internacionales vinculados estrechamente con los derechos humanos y el buen gobierno. El OGP no es un tratado internacional, sino una asociación multilateral a la cual pueden adherir los países de manera voluntaria, definiendo en función del contexto de cada nación, un plan de acción avalado y diseñado entre gobierno y sociedad civil.

Al suscribir la declaración de gobierno abierto, los países se comprometen a "fomentar una cultura de gobierno abierto que empodere y brinde resultados a los ciudadanos, y promueva los ideales del gobierno abierto 
y participativo" (www.opengovpartnership.org, consultado el 11 de noviembre de 2013). Ramírez (2011: 107) indica que existe un marco jurídico nacional, asociado a la práctica de gobierno abierto, siendo principalmente:

a) la legislación sobre el acceso a la información y libertad de prensa; b) la legislación sobre privacidad y protección de datos; c) las leyes sobre procedimientos administrativos; d) la legislación sobre defensores del pueblo (Ombudsman); y e) las leyes sobre las entidades fiscalizadoras superiores.

La iniciativa multinacional agrupa a la fecha más de 60 países, así como a un importante número actores de la sociedad civil, en igual número de países. De acuerdo al portal del OGP, para ser elegibles los gobiernos deben demostrar un nivel mínimo de compromiso relacionado a principios de gobierno abierto en cuatro áreas claves (transparencia fiscal, acceso a la información, declaraciones patrimoniales y participación ciudadana), y cumplir con al menos el $75 \%$ de los criterios de elegibilidad.

El siguiente paso es la elaboración de un plan de acción conjunto, entre gobierno y sociedad civil, que enliste una serie de asuntos que merecen atención del gobierno. Al ingresar al OGP, se asume el compromiso de implementar estos asuntos en un determinado plazo e integrar un mecanismo de evaluación independiente. Hacia 2014, son 16 países latinoamericanos los que han formulado agendas de gobierno abierto, la mayoría de ellos han concluido el ciclo de la primera agenda común, rescatando importantes aprendizajes por tropicalizar desde la iniciativa internacional.

Durante 2012 y 2013, se identifica en la región latinoamericana dos casos representativos, seleccionados en base a lo siguiente: 1) entre los fundadores del OGP se ubica México; 2) países con más desarrollo en gobierno electrónico de acuerdo a la CEPAL, los cuales se ubican en el grupo 1 de acuerdo a la tipología de Naser y Concha (2012): Colombia, Chile, Uruguay, Argentina, México, Brasil y Barbados; 3) los países que son referencia en transparencia, de acuerdo al estudio de Associated Press, citado por Gascó (2013): Chile, República Dominicana, Guatemala, México y Uruguay.

Estos criterios, conducen a seleccionar a Chile y México, por tratarse de los países que más repiten en las posiciones de cada criterio, además de haber sido sede de los únicos dos encuentros regionales del OGP. 


\section{CHILE: LA MOderNización DEL SECTOR PÚBlico COMO VÍA PARA UN GOBIERNO ABIERTO}

En junio de 2012, Chile presentó en la cumbre de Brasilia su primer plan de acción de gobierno abierto. Posteriormente, elaboró y publicó el Instructivo Presidencial N. ${ }^{\circ}$ 005, del 12 de noviembre de 2012, el cual define el rumbo que el Estado chileno tomaría para alcanzar un gobierno abierto, estableciendo dos vías:

1. Un portal de gobierno abierto como ventanilla única. La idea es centralizar una plataforma para iniciativas de transparencia, participación y datos abiertos, bajo ciertos estándares que habrán de observar las instituciones públicas.

2. La política de datos abiertos para incentivar la participación de la sociedad. Para ello se liberó el Portal de datos abiertos en su versión beta, con la idea de ir mejorando la aportación ciudadana. Este portal consolidará la transparencia activa en los términos de la Ley N. ${ }^{\circ}$ 20.285 sobre Acceso a la Información Pública.

El instructivo representa un cambio centrado en el nivel macro o institucional. $\mathrm{Al}$ abordar la forma de organizarse para procesar los cambios que exige el OGP, se designó al Ministerio de la Secretaría General de la Presidencia (SEGPRES), como responsable de avanzar en la deliberación, negociación y consenso del diseño, implementación y evaluación de gobierno abierto. También ha sido el responsable de implementar los proyectos de modernización del Estado y redes basadas en las TICs para hacer más eficiente, transparentar y abrir el gobierno a la participación. La SEGPRES delega en dos áreas las actividades relacionadas con gobierno abierto: la Comisión Defensora Ciudadana y de Transparencia (CDT), designada como responsable de la relación con las organizaciones de la sociedad civil y el OGP; y la Unidad de Modernización y Gobierno Digital, responsable de coordinar los esfuerzos hacia el interior de la Administración para mejorar la eficiencia de los servicios públicos, e implementar la red multiservicios Chile Atiende.

Al designar el instructivo presidencial a la Unidad de Modernización y Gobierno Digital como autoridad, definió una ruta instrumental con visión tecnológica, como vía para lograr un gobierno abierto, éste último forma uno de los tres pilares del Estado Chileno: gobierno cercano, gobierno abierto y gobierno eficiente. Esta normativa, define gobierno abierto como plataforma para la modernización del Estado. Ya en su segundo plan de acción publicado en agosto de 2013, Chile brinda una segunda definición de gobierno abierto, en términos de 
Una política pública de carácter transversal en el Estado chileno, cuyo propósito es fortalecer y mejorar la institucionalidad y gestión de los asuntos públicos a partir de promover y consolidar la aplicación de los principios de la transparencia y acceso a la información pública, y los mecanismos de participación ciudadana en el diseño, formulación, ejecución y evaluación de las políticas. Todo ello en el contexto del proceso de modernización de las instituciones públicas en curso, cuya finalidad es avanzar hacia un Estado al servicio de todos y a mejorar la calidad de vida de la población (Gobierno de Chile 2013: 2).

La CDT es la instancia coordinadora y responsable de negociar, diseñar, consensar e implementar el gobierno abierto como política pública. En Chile, el gobierno abierto encuentra su pilar más trascendente en una agenda modernizadora de gobierno electrónico, experiencia que retoma, impulsa y dirige en acciones de mejora del servicio público. El lanzamiento del Portal de Transparencia y el Portal de Datos Abiertos chilenos, define la estrategia para abrir el gobierno en Chile.

Chile y México tienen en común la existencia de una crisis relacional entre gobierno y sociedad. Pero a diferencia de México, Chile continuó con la implementación de su primer plan de acción, sin la participación activa de los actores iniciales de la sociedad civil. Las posturas divergentes entre sus integrantes evitaron que la sociedad civil ejerciera un contrapeso a la decisión del gobierno en temas incluidos en la primera agenda de gobierno abierto. El Consejo para la Transparencia se mostró pasivo, y evitó intervenir en la formulación y seguimiento del primer plan de acción. A propósito de la dificultad de consensar el primer plan de acción, Sánchez y Contreras (2012) detallan la insatisfacción sobre este particular, y analizan el caso de Chile con respecto de la relación del derecho de acceso a la información pública y los trabajos realizados en el OGP.

En el marco de este proceso, las observaciones presentadas por la Sociedad Civil y el Consejo para la Transparencia no fueron mayormente consideradas, especialmente en lo que refiere a la metodología para seleccionar las medidas que integran el plan y el monitoreo. Por este motivo, dicho plan corresponde más bien a un plan de gobierno (Sánchez y Contreras 2012: 29).

En una concepción multinivel de gobierno abierto, los cambios que Chile introdujo en su marco legal muestran que es una nación muy joven en el tema de la transparencia, apenas tiene su ley de transparencia en 2008. Por ello, ha debido ir ajustando su norma. Algunos cambios importantes propuestos en el primer plan de acción, como la Ley de Lobby y la de 
Partidos Políticos, diseñan un marco institucional relevante de orden normativo, aun cuando en su visión predomina la ruta tecnológica.

A nivel macro, queda apuntado que en la Ley de Transparencia se identifican dos tipos de transparencia, una activa y otra pasiva. La primera alude a la información que obligatoriamente debe subirse a páginas de Internet y actualizarse al menos una vez al mes. Es la información indispensable que se otorga al ciudadano sin mediar petición de parte, como la estructura organizativa, la información presupuestal, documentos que consten actos, resoluciones, entre otros.

La transparencia pasiva comprende el derecho de acceso a la información pública que requiere de petición, y se sustenta a su vez en once principios que amparan este derecho fundamental: relevancia, libertad de información, apertura o transparencia, máxima divulgación, divisibilidad, facilitación, no discriminación, oportunidad, control, responsabilidad y gratuidad.

Los cambios en la forma de organizar el gobierno (meso), se observan mediante la sistematización de sus servicios públicos y la creación del Portal de Datos Abiertos, práctica reconocida con un premio otorgado por la Red de Gobierno Abierto con sede en Argentina, un tema que aún no se ha consolidado en México. El estudio del caso de Chile, revela las dificultades en sus inicios, por avanzar a nivel micro, dado la relación de baja intensidad con grupos organizados de la sociedad, mientras que en México existe una relación de alta intensidad, como se verá adelante.

El OGP, a través del Mecanismo de Reporte Independiente (IRM, por sus siglas en inglés), viene publicando resultados de los países integrantes, e identifica las acciones de impacto en términos de lo relevante para el OGP, siendo en el plan de acción de Chile, lo siguiente: 1) el Portal de Datos Abiertos, 2) el proyecto de Ley de Probidad de la Función Pública, 3) el Portal de Transparencia, 4) el proyecto de Ley de Lobby, 5) el proyecto de Ley de Partidos Políticos, 6) la promoción de la participación ciudadana y 7) la Participación ciudadana en materia medioambiental.

La evaluación en cada uno de los temas apuntados, indica que el $29 \%$ de las acciones relevantes gozan de impacto transformador (números $4 \mathrm{y}$ 7), mientras que el restante $71 \%$ son de impacto moderado. Los actores sociales más destacados en la agenda de gobierno abierto, son Ciudadano Inteligente, Chile Transparente y la Fundación ProAcceso. Como actor que mantuvo neutralidad en el primer plan de acción se conoce al Consejo para la Transparencia, mientras el actor que lo implementó activamente fue la SEGPRES. 


\section{MÉXICO: INNOVADOR PARA PROCESAR ACUERDOS DE GOBIERNO ABIERTO}

México destaca en transparencia y acceso a la información, por el alto grado de institucionalización e innovación. Desde 2003 dispone de un sistema eficiente en línea, para realizar peticiones de acceso a la información pública. $\mathrm{Al}$ momento son 25 entidades federativas del país las que están vinculadas al sistema Infomex, mediante convenio suscrito con el Instituto Federal de Acceso a la Información Pública y Protección de Datos Personales (IFAI).

El componente de la participación, es igualmente destacado en términos del alto perfil profesional y la expertise ciudadana en temas tecnológicos, transparencia, acceso a la información y rendición de cuentas. México es país fundador del OGP, no por ello exento de obstáculos por superar en el diseño e implementación de su primer plan de acción. El primer aspecto que actores de la sociedad civil pusieron a debate a partir de septiembre de 2011, es el relativo al diseño de las acciones descritas en su primer plan de acción. La inconformidad manifestada consistió en destacar la ausencia de indicadores medibles, la redacción confusa de algunas acciones, así como el seńalamiento de la existencia de ciertas acciones que ya estaban en implementación desde antes de ingresar al OGP, lo que tuvo efectos de singular impacto.

Durante los primeros meses de la implementación del plan, entre septiembre y diciembre de 2011, se presentó una crisis relacional entre gobierno y actores de la sociedad civil, que activó el riesgo de cancelar la participación de grupos organizados de la sociedad civil, al no sentirse representados en el primer plan de acción. En este contexto, se presentaron condiciones de cambio respecto a la forma y contenido del primer plan de acción. Entre diciembre y mayo de 2012, se elaboró una nueva versión del plan de acción, donde las acciones formuladas consistían ahora en demandas que las organizaciones de la sociedad civil estaban impulsando y otras que deseaban fueran atendidas desde la agenda de gobierno. De algún modo, se abandonó un plan de acción gubernamental, para ampliarse hacia un nuevo plan de acción más societal.

La creación del Secretariado Técnico Tripartita (STT), en diciembre de 2011, es producto de esta etapa de crisis. Durante la implementación del primer plan de acción, el STT se constituyó en el órgano deliberativo y decisor, de los acuerdos tomados entre los representantes de los tres actores centrales en el tema de gobierno abierto: 1) la Secretaria de la Función Pública (SFP), que contó con dos instancias coordinadoras del esfuerzo gubernamental, la Unidad de Gobierno Digital (UGD) y la Unidad de Políticas de Transparencia y Cooperación Internacional (UPT), siendo ésta última, la representación oficial y única del Gobierno de México ante el 
OGP; 2) el IFAI con la representación depositada en la Presidencia y la Secretaría Ejecutiva del IFAI; 3) organizaciones de la sociedad civil. Entre ellas se cuentan FUNDAR Centro de Análisis e Investigación, como su representante del resto de actores de sociedad civil en gobierno abierto, el Instituto Mexicano de la Competitividad (IMCO), Artículo 19, el Centro de Investigación para el Desarrollo (CIDAC), CitiVox; Cultura Ecológica; Gestión Social y Cooperación (GESOC) y Transparencia Mexicana.

En el STT, cada uno cuenta con voz y voto, en igualdad de condiciones. La colaboración ha sido palpable en el seno del STT y verificable mediante las cédulas que se publican en la página web del OGP-México. Aun con la existencia de una instancia deliberativa y ejecutiva, no se identificaron cambios en el nivel macro o institucional, es decir, un cambio de reglas del funcionamiento de la Administración Pública Federal. No obstante, el STT tuvo la capacidad de cumplir con una función reductora de complejidad, en la relación gobierno y actores de sociedad civil, pese a que el STT no es una adscripción de la estructura orgánica de la Administración Pública Federal de México. Tal condición ha facilitado, hasta la fecha, cierto grado de flexibilidad en su funcionamiento, el proceso de confección de acuerdos, la implementación de acciones y el diseño de un segundo plan de acción en gobierno abierto.

México mostró pocos cambios organizacionales (nivel meso) entre 2011 y 2013, aunque algunos de ellos son significativos, como la firma y kiosco electrónicos para eliminar el uso de papel en el envío de oficios entre dependencias públicas, el Programa de Mejoramiento de la Gestión Pública y el buscador web de información exclusiva del gobierno federal.

A nivel micro, el STT validó las acciones concretas que formaron el primer plan de acción (ampliado) de México, cuya vigencia fue de seis meses, a partir de junio de 2012. Ello obligó a realizar con prontitud las acciones comprometidas. El informe rendido en octubre de 2012 por la SFP, a través de la UPT, consistió en la publicación de una memoria documental, que indica los resultados alcanzados en corto tiempo. En un comunicado de prensa de noviembre de 2012, la SFP estableció un nivel de cumplimiento de más del $90 \%$ de cumplimiento global de las acciones comprometidas.

Por su parte, las organizaciones de la sociedad civil de México realizaron por cuenta propia su propia evaluación al primer plan de acción (original y ampliado), valorando un total de 38 compromisos. Los aspectos evaluados son 1) disponibilidad y actitud del gobierno; 2) programa de trabajo específico; 3) tiempo de respuesta; 4) avances sobre planes de trabajo; y 5) calidad del cumplimiento de la propuesta. Los resultados fueron 
clasificados en los siguientes criterios: cumplimientos totales, 21 (55\%); cumplimientos parciales, 15 (40\%); cumplimientos nulos, 2 (5\%). Al sumar los compromisos con cumplimiento total y parcial, se tiene un $95 \%$ de cumplimiento del primer plan de acción.

La evaluación 2011-2013 realizada por el IRM al plan de acción mexicano, establece el cumplimiento total de 17 acciones realizadas en tiempo, sin especificar cuáles son las de mayor impacto para el OGP, se describen enseguida: 1) contar con sitios web de los servicios públicos; 2) desarrollar herramientas de la innovación para sociedad civil; 3) contar con un catálogo de programas sociales; 4) incrementar el número de empresas involucras en la rendición de cuentas corporativa; 5) adherir a la Iniciativa de Industrias Extractivas; 6) realizar una lista de beneficiarios de subsidios; 7) mejorar la calidad de bases de datos; 8) crear una base de datos sobre proyectos mineros; 9) mejorar el sistema electrónico de compras; 10) elaborar el micro sitio del Servicio de Administración Tributaria; 11) elaborar el motor de búsqueda de regulaciones del Telecom, 12) elaborar el motor de búsqueda de órganos reguladores de Energía;13) elaborar el motor de búsqueda de órganos reguladores de Aeronáutica;14) elaborar un sitio web de derecho de acceso a la información pública; 15) hacer sinergias con plataformas existentes de derecho de acceso a la información; 16) contar con archivos web y documentos en formato de datos abierto; $y$ 17) crear un sitio web sindical con información actualizada (OGP 2014b).

De acuerdo al IRM, se logró el cumplimento final de 20 acciones (17 en tiempo y 3 más después del plazo previsto para su realización), lo que representan el 54\% de las 37 acciones evaluadas, 14 (38\%) se definen en proceso de cumplirse y $3(8 \%)$ son acciones que no se ejecutaron.

Durante la implementación del plan de acción mexicano, las secretarías de Estado continuaron su funcionamiento tradicional, lo que dificultó al representante gubernamental cumplir con algunos compromisos contraídos en el OGP. Es decir, el gobierno presentaba inercias, aun cuando existían agentes de cambio en la representación gubernamental del OGP. El liderazgo mostrado por todos los integrantes del STT, resultó ser un factor clave para lograr avanzar en los compromisos contraídos.

Existieron intentos de la SFP para implantar un marco de interoperabilidad, pero no se logró cumplir. Los cambios más relevantes en gobierno abierto, han sido al nivel micro, o de política pública, donde la transparencia modificó su política focalizada, para asumir en 2013 una política de transparencia activa. La visión de gobierno abierto, entre 2011 y 2013, era de orden político con ciertas metas tecnológicas, aunque en septiembre de 2013 se anunció la Agenda Digital de Gobierno Abierto, 
a cargo de la Oficina de la Presidencia de la República. A partir de ahí se formalizó la intervención desde la Oficina Presidencial en la agenda de gobierno abierto, para diseñar el segundo plan de acción. Sin dejar de continuar la SFP con la representación gubernamental, la Oficina de la Presidencia para la Estrategia Digital Nacional, junto con el IFAI y organizaciones de la sociedad civil, se dieron a la tarea de desarrollar una definición de gobierno abierto en términos de gobernanza y buen gobierno, lo que representa un aprendizaje relevante, en términos de lo desarrollado en el OGP:

[El] Gobierno abierto es un nuevo modelo de gobernanza que busca transformar la relación entre gobierno y sociedad para fortalecer nuestra democracia. Se trata de crear un ecosistema que posiciona al gobierno como plataforma de innovación (Gobierno de México 2014: 5).

La definición mantiene un doble carácter en la aspiración de un gobierno abierto en México, que lo traducen en un modelo de gobernanza democrática, a la vez que plataforma para la innovación.

Con las reformas a la Ley Orgánica de la Administración Pública Federal, en diciembre de 2012, se modificó el escenario y es altamente probable que la Oficina Presidencial para la Estrategia Digital obtenga la representación gubernamental que ostenta la SFP en el OGP, y por lo tanto, sería el actor de gobierno con presencia en el STT. Aun cuando las reformas a la administración pública extinguen a la SFP, permanece vigente en 2014 ejerciendo sus atribuciones en virtud de artículos transitorios, en tanto se crea la Agencia Anticorrupción como nuevo organismo constitucional autónomo del Estado mexicano.

\section{Una mirada de contraste entre Chile y México}

Chile y México han concluido el primer plan de acción y están en etapa de implementación de un segundo plan de acciones de gobierno abierto, donde reconocen la importancia de fortalecer la participación ciudadana. La siguiente tabla, indica los dos ejes predominantes a partir de una sumatoria que arroja un acumulado del $70 \%$ o más de las acciones realizadas. 


\section{Tabla 2: Evaluación del IRM sobre las acciones del primer plan de acción de OGP}

$\begin{array}{cccccc}\text { País } & \begin{array}{c}\text { Número } \\ \text { total de } \\ \text { acciones }\end{array} & \begin{array}{c}\text { Avance } \\ \text { IRM }\end{array} & \begin{array}{c}\text { Acciones } \\ \text { relevantes } \\ \text { según el } \\ \text { OGP }\end{array} & \begin{array}{c}\text { Eje } \\ \text { predominante } \\ \text { (1) de OGP }\end{array} & \begin{array}{c}\text { Eje } \\ \text { predominante } \\ \text { (2) de OGP }\end{array} \\ \text { Chile } & 19 & 79 \% & 37 \% & \begin{array}{c}\text { Incremento de } \\ \text { la integridad } \\ \text { pública }(57,9 \%)\end{array} & \begin{array}{c}\text { Mejoramiento } \\ \text { de servicios } \\ \text { públicos } \\ (21,05 \%)\end{array} \\ \text { México } & 37 & 54 \% & \text { Sin definirlo } & \begin{array}{c}\text { Gestión eficaz } \\ \text { de los recurso } \\ \text { públicos } \\ (4,71 \%)\end{array} & \begin{array}{c}\text { Incremento de } \\ \text { la integridad } \\ \text { pública } \\ (31,43 \%)\end{array} \\ & & & & & \end{array}$

Fuente: Elaboración propia a partir de OPG (2014a, 2014b).

Chile y México, cuentan con virtudes y problemáticas determinadas en gran parte por el contexto, la tradición e historia de sus instituciones, actores y sistemas. México es relevante en términos de la visión política, no para negar la visión tecnológica, sino para destacar como la política resultó una variable explicativa en el proceso innovador de creación del STT y el intento por generar datos abiertos en distintos temas de transparencia. Chile dispuso de una importante tradición en agenda de gobierno electrónico, que le favoreció para poner en marcha una perspectiva tecnológica de gobierno abierto, y profundizar en un enfoque basado en la prestación de servicios públicos y la creación de un repositorio de datos abiertos.

Aun así, la visión tecnológica en Chile del gobierno abierto se ocupó de establecer un marco legal para diseñar e implementar acciones que responden también a una visión política de gobierno abierto, como es la Ley de Lobby y la de Participación Ciudadana Ambiental. Chile se enfocó en el primer plan de acción a su marco institucional y, en el segundo plan de acción, el Consejo para la Transparencia y las organizaciones de la sociedad civil están retomando un rol activo en el diseño y elaboración del mismo, el cual se desarrolló bajo un proceso más amplio de consulta, consensuado entre todos los actores. La confianza entre los actores del gobierno abierto ha cobrado vigencia en Chile.

México ha puesto la mirada para un segundo plan de acción en una visión más aplicada a la agenda tecnológica para la innovación en el sector público, pero sin renunciar a lo avanzado en términos de una visión política, como el STT y la incorporación al ciclo de la gestión pública de las acciones de gobierno abierto. El primer plan de acción, posteriormente 
ampliado, denota el resultado de amplia deliberación entre Gobierno Federal, el IFAI, y actores expertos de la sociedad civil. Los acuerdos tomados en el STT son más ejecutivos que de orden consultivo, lo que sugiere validez y eficacia en los acuerdos alcanzados. México aún no tiene incidencia a nivel sub-nacional y local en el tema gobierno abierto, sus avances están circunscritos al gobierno federal, lo que representa un área de oportunidad para el fortalecimiento de la transparencia y la participación ciudadana en las entidades federativas y municipios en México.

Ambos casos ilustran la importancia de incorporar acciones de gobierno abierto al ciclo de la gestión pública, además de contrastar, bajo contextos distintos, ciertas variables que influyen en gobierno abierto multinivel.

\section{REFLEXIÓN FINAL}

La propuesta multinivel para analizar el gobierno abierto es un lente útil para mirar las áreas de oportunidad e instrumentar el cambio más factible, de acuerdo al contexto de cada país. Si bien el OGP presenta casos de éxito, su enfoque está centrado en el respeto de la autonomía de actores sociales y políticos de cada nación, en la búsqueda de la convergencia sobre las acciones a seguir y el diseño de mecanismos para procesar la divergencia.

En el nivel macro, donde el desarrollo institucional es relevante en términos de nuevas reglas y el fortalecimiento de las reglas vigentes para lograr gobiernos más abiertos, ciertos países muestran madurez a este nivel de análisis. Chile expresó su interés en el nivel institucional (macro), al incorporar acciones en el primer plan, temas que atańen al Parlamento. La iniciativa de leyes vinculadas al fortalecer la integridad pública, como el lobby y la participación, sugiere intentos de institucionalizar ciertos temas de la agenda de gobierno abierto.

A nivel meso, la organización pública sugiere, mediante la visión política y la visión tecnológica, formas organizativas que puede adoptar, de acuerdo a su definición de gobierno abierto. Ambas visiones son polos complementarios en la consecución de fines y medios para abrir el gobierno, pero no se manifiestan de forma pura en la realidad, sino que son la suma de atributos que caracterizan posiciones particulares. Las visiones que se proponen son rutas yuxtapuestas a seguir a nivel meso, para argumentar que son visiones complementarias.

El nivel micro es donde el OGP ha sido más exitoso. Pocos países han modificado sus reglas y forma de organizar sus entidades públicas, pero es innegable que los países integrantes del OGP desarrollan políticas públicas de gobierno abierto, implementan acciones de datos abiertos, promueven 
los principios de buen gobierno e intentan avanzar en una concepción de la transparencia, así como de participación ciudadana.

No obstante, quedó mostrado que la teoría y la práctica mantienen una importante brecha que se reduciría, según se procese el conocimiento obtenido en la curva de aprendizaje. Ambos países analizados elaboraron para el segundo plan una definición de gobierno abierto que combina atributos de las visiones tecnológica y política, poniendo énfasis en cierto aspecto en particular. En los países miembros del OGP, las probabilidades de observar acciones vinculadas a transformar la organización y el marco institucional del gobierno, son altas de mantenerse las condiciones de aprendizaje, pero es fundamental mantener la rendición de cuentas entre actores del OGP y marcos transparentes en el procesamiento de los acuerdos tomados entre gobierno y actores de sociedad civil. Se trata de generar confianza sistémica para superar las barreras políticas, potenciales crisis relacionales y la simulación de acciones sin resultados tangibles.

Tres grandes retos se enuncian, a manera de futuras líneas de investigación y atención práctica en gobierno abierto: 1) la creación de una estructura de incentivos para reducir la complejidad de la relación gobierno y sociedad, es decir, producir confianza entre actores; 2) adoptar una definición multinivel de gobierno abierto con indicadores medibles; y 3) la apropiación de una cultura de la transparencia colaborativa en el servicio público. 


\section{REFERENCIAS}

Arellano, D. (2010). El Enfoque Organizacional en la Política y Gestión Públicas. Entendiendo las Organizaciones Gubernamentales. En Merino et al., Problemas, decisiones y soluciones. Enfoques de Politica Pública. México: Fondo de Cultura Económica-CIDE.

Calderón, C. y Lorenzo, S. (2010). Open Government: Gobierno Abierto. Alcalá: Algón.

Cohen, J. (2001). Democracia y Libertad. En Jon Elster (Ed.), La Democracia Deliberativa. Barcelona: Gedisa.

Dahl, R. (1992). La Democracia y sus Criticos. Barcelona: Paidos.

Denhardt, R. y Denhardt, J. (2000). The New Public Service. Serving Rather than Steering. Public Administration Review, 60 (6), 549-559.

Deutsch, K. (1998). Política y Gobierno. México: Fondo de Cultura Económica.

Elster, J. (2001). La democracia Deliberativa. Barcelona: Gedisa.

Fung, A. y Weill, D. (2010). Open Government and Open Society. En Lathrop, D. y Laurel R. (Ed.), Open Government. Collaboration, Transparency, and Participation in Practice. Sebastopol: O'Reilly.

Fuster, M. y Subirats, J. (2013). Gobierno Abierto y Políticas Públicas. Los Dilemas de un Proceso Inevitable. Telos, 45, 1-4.

Gambetta, D. (2001). ¡Claro!: Ensayo sobre el Machismo Discursivo. En Jon Elster (Ed.), La Democracia Deliberativa. Barcelona: Gedisa.

Gascó, M. (2013). No es Oro Todo lo que Reluce: ¿Qué Hay Detrás de las Promesas de Gobierno Abierto en Iberoamérica? Ponencia presentada en el XVIII Congreso del CLAD, 29 de octubre al 1 de noviembre, Montevideo, Uruguay.

Gobierno de Chile. (2012). Plan de Acción de la Alianza por el Gobierno Abierto. Santiago: Alianza por el Gobierno Abierto.

(2014). Plan de Acción de la Alianza por el Gobierno Abierto. Santiago: Alianza por el Gobierno Abierto.

Gobierno de México. (2011). Plan de Acción de la Alianza por el Gobierno Abierto. México DF: Alianza por el Gobierno Abierto. 
. (2014). Plan de Acción de la Alianza por el Gobierno Abierto. México DF: Alianza por el Gobierno Abierto.

Guardián, C. (2010). ¿Transparencia? En Calderón, C. y Lorenzo, S. (Coords.), Open Government: Gobierno Abierto. Alcalá: Algón.

Habermas, J. (2005). Factibilidad y validez. Sobre el Derecho y el Estado Democrático de Derecho en Términos de Teoría del Discurso. España: Trotta.

Jiménez, C. y Gascó, M. (2012). Elementos Relevantes en la Transposición e Implantación de los Marcos Nacionales de Interoperabilidad. Ponencia presentada en el XVII Congreso del CLAD, 30 de octubre al 2 de noviembre, Cartagena de Indias, Colombia.

Jiménez, C. (2013). Sobre el Término Open Government y su Aparición Documentada. Blog de Estratic. Disponible http://estratic.wordpress. com/2013/04/04/el-termino-open-government-aparece-en-los-anos50-no-en-los-70/ [25-03-2013].

Mariñez, F. (2013). ¿Qué Transparencia Requiere el Gobierno Abierto? Revista de Gestión Pública, II (2), 303-333.

Mariñez, F. y Valenzuela, R. (2013). Gobierno abierto: ¿Más innovaciones? ¿Más gobierno? ¿Más sociedad? ¿En qué consiste? Propuestas para los gobiernos locales. México: Miguel Ángel Porrúa.

Meijer, A., Curtin, D. y Hillebrandt, M. (2012). Open Government: Connecting Vision and Voice. International Review of Administrative Sciences, 78 (1), 10- 29.

Meyer, J. y Rowan, B. (2001). Organizaciones Institucionalizadas: La Estructura Formal Como Mito y Ceremonia. En Powell, W. y DiMaggio, P. (Comps.), El Nuevo Institucionalismo en el Análisis Organizacional. México: Fondo de Cultura Económica.

Naser, A. y Concha, G. (2012). Panorama de Gobierno Electrónico en la Región: Resultados e Impactos. En Concha, G. y Naser, A. (Eds.), El desafío hacia el Gobierno Abierto en la Hora de la Igualdad. Santiago de Chile: CEPAL.

Noveck, B. (2009). Wiki Government. How Technology Can Make Government Better, Democracy Stronger, and Citizens more Powerful. Washington: Brooking Institution Press. 
Noveck, B. (2010). The Single Point of Failure. En Lathrop, D. y Laurel R. (Ed.), Open Government. Collaboration, Transparency, and Participation in Practice. Sebastopol: O’Reilly.

Obama, B. (2009). Open Government Directive. Washington: Executive Office of the President of United States.

Open Government Partnership (OGP). (2012). Reporte de Cumplimiento Elaborado por el Secretariado Técnico Tripartita de México. México: OPG.

(2014a). Mecanismo de Revisión Independiente: México Informe de Avance 2012-2013. México: OGP.

(2014b). Mecanismo de Revisión Independiente: Chile Informe de Avance 2012-2013. Santiago de Chile: OGP

Oszlak, O. (2012). Gobierno Abierto: Promesas, Supuestos, Desafíos. Ponencia presentada en la VIII Conferencia Internacional de INPAE, 25 de abril, Rio Piedras, Puerto Rico.

Parks, W. (1957). The Open Government Principle: Applying the Right to Know Under the Constitution. The George Washington Law Review, $26(1), 1-22$.

Popper, K. (2006). La Sociedad Abierta y sus Enemigos. Barcelona: Paidos.

Powell, W. y DiMaggio, P. (2001). Retorno a la Jaula de Hierro: El Isomorfismo Institucional y la Racionalidad Colectiva en los Campos Organizacionales. En Powell, W. y DiMaggio, P. (Comps.), El Nuevo Institucionalismo en el Análisis Organizacional. México: Fondo de Cultura Económica.

Prince, A. y Jolías, L. (2013). Las Fuentes Conceptuales del Gobierno Abierto. Telos, 94, 48-57.

Ramírez, Á. (2011). Gobierno Abierto y Modernización de la Gestión Pública: Tendencias Actuales y el (Inevitable) Camino que Viene. Reflexiones Seminales. Enfoques, IX (15), 99-125.

Rawls, J. (2005). Teoría de la Justicia. México: Fondo de Cultura Económica.

Rochet, C., Keramidas, O. y Bout, L. (2008). Crisis as Change Strategy in Public Organizations. International Review of Administrative Sciences, 74 (1), 65-77. 
Sánchez, M. y Contreras, J. (2012). El Acceso a la Información y la Alianza de Gobierno Abierto (OGP) en Chile. En Alianza Regional por la Libre Expresión y la Información, Saber Más IV. Informe Regional sobre el Acceso a la Información Pública y la Alianza por el Gobierno Abierto. Santiago de Chile: Alianza Regional.

Scott, R. y Meyer, J. (2001). La Organización de los Sectores Sociales: Proposiciones y Primeras Evidencias. En Powell, W. y DiMaggio, P. (Comps.), El Nuevo Institucionalismo en el Análisis Organizacional. México: Fondo de Cultura Económica.

Secretaría de la Función Pública (SFP). (2012). Memoria documental. Unidad de Politica de Transparencia y Cooperación Internacional. México: SFP.

Simon, H. (2001). ¿Por Qué la Administración Pública? Revista de Economía Institucional, 4, 119-122.

Subirats, J. (2012). Nuevos Tiempos. ¿Nuevas Políticas Públicas? Explorando Caminos de Respuesta. Ponencia presentada en el XVII Congreso del CLAD, 30 de octubre al 2 de noviembre, Cartagena de Indias, Colombia.

Uvalle, R. (2013). Oportunidadesy Restricciones de la Politica de Transparencia en México. México: UNAM.

Valenzuela, R. (2012). De la Periferia al Centro. Análisis de un Gobierno Abierto como Vía para la Consolidación de la Democracia en México. En Comisión Estatal Electoral de Nuevo León, XIII Certamen de Ensayo Politico. Monterrey: Comisión Estatal Electoral de Nuevo León.

Valenzuela, R. (2013). Delimitar Gobierno Abierto para Ampliar la Colaboración con una Sociedad Más Abierta. Estado, Gobierno y Gestión Pública. Revista Chilena de Administración Pública, 21, 127- 158.

Vercelli, A. (2010). Datos, Informaciones, Obras y Gobiernos Abiertos a los Ciudadanos. En Calderón, C. y Lorenzo, S. (Coords.), Open Government: Gobierno Abierto. Alcalá: Algón.

Vergara, R. (2010). Organización e Instituciones, México: BBAP DF.

Villoria, M. (2012). Transparencia y Gobierno Abierto: ¿Qué Gobierno quiere el Gobierno Abierto? Ponencia presentada en el XVII Congreso del CLAD, 30 de octubre al 2 de noviembre, Cartagena de Indias, Colombia. 
Weber, M. (2005). ¿Qué es la burocracia? Buenos Aires: Leviatán.

Welch, E. (2012). The Relationship between Transparent and Participatory Government: A Study of Local Governments in the United States. International Review of Administrative Sciences, 78 81), 93-115.

Yu, H. y Robinson, D. (2012). The New Ambiguity of Open Government. Law Review Discourse, 59, 178- 208.

\section{Leyes}

Ley N. 20.285, sobre Acceso a la Información Pública, República de Chile.

Ley Orgánica de la Administración Pública Federal, Estados Unidos Mexicanos.

Recibido: 14-03-2014

Aceptación de la versión final: 28-05-2014 